\title{
Experimental Acoustic Evaluation of an Auditorium
}

\author{
Marina Dana Ţopa, ${ }^{1}$ Norbert Toma, ${ }^{1}$ Botond Sandor Kirei, ${ }^{1}$ \\ Ioana Sărăcuţ, ${ }^{1}$ and Angelo Farina ${ }^{2}$ \\ ${ }^{1}$ Basis of Electronics Department, Faculty of Electronics, Telecommunications and Information Technology, \\ Technical University of Cluj-Napoca, 400114 Cluj-Napoca, Romania \\ ${ }^{2}$ Industrial Engineering Department, University of Parma, 43121 Parma, Italy
}

Correspondence should be addressed to Marina Dana Ţopa, marina.topa@bel.utcluj.ro

Received 3 April 2012; Revised 26 June 2012; Accepted 27 August 2012

Academic Editor: Joseph CS Lai

Copyright ( $) 2012$ Marina Dana Ţopa et al. This is an open access article distributed under the Creative Commons Attribution License, which permits unrestricted use, distribution, and reproduction in any medium, provided the original work is properly cited.

The paper presents a case history: the acoustical analysis of a rectangular auditorium. The following acoustical parameters were evaluated: early decay time, reverberation time, clarity, definition, and center time. The excitation signal was linear sweep sine and additional analysis was carried out: peak-to-noise ratio, reverberation time for empty and occupied room, standard deviation of acoustical parameters, diffusion, and just noticeable differences analysis. Conclusions about room's destination and modeling were drawn in the end.

\section{Introduction}

Nowadays, the most important events (conferences, concerts) take place in enclosed spaces, where the sound waves are reflected from the walls, ceiling, and floor, giving birth to the reverberation phenomenon [1-3]. This phenomenon can be evaluated subjectively as pleasant (in a concert hall, it can contribute to spatial sensation for music listeners) or irritating (in a conference hall, it could be a factor of unintelligibility of speech).

An objective classification is achieved with acoustical parameters extracted from the impulse response of the room [4-7]. Thus, accurate impulse response measurements, already regulated by ISO 3382 standard, are desired for the assessment of acoustical properties. In our work, we chose to measure the impulse response using a linear sweep sine as excitation and compute the acoustical parameters with professional software.

The paper is dedicated to the acoustic evaluation of an auditorium. The acoustical parameters of the room were computed in several points. The destination of the room was provided by the analysis altogether with information about the minimum measurement points.

The paper is organized as follows. Section 2 presents the objective acoustical parameters used to evaluate the properties of a room as well as the relation between objective and subjective (perceptual) parameters. Section 3 describes the equipment used to evaluate the acoustics as well as the software for processing the measured samples. Section 4 is dedicated to the estimation of acoustical properties of the analyzed auditorium. The last section presents the final conclusions altogether with the comments related to the acoustical properties of the auditorium.

\section{Evaluated Acoustical Parameters}

2.1. Objective Parameters. The acoustical parameter evaluation is based upon the measurement of the impulse response $h(t)$ and the computation of the energy decay curve (EDC) [4]:

$$
\operatorname{EDC}(t)=\int_{t}^{\infty} h^{2}(\tau) d \tau
$$

The EDC is the graphical representation of the decay of the sound pressure level in a room with respect to time, after the sound source has stopped. It is possible to measure this decay either after the actual cutoff of a continuous sound source in the room or derived from the reverse-time integrated squared impulse response of the room. EDC for 
TABLE 1: Schultz's estimated change in RT values.

\begin{tabular}{lc}
\hline Frequency $(\mathrm{Hz})$ & DT $(\mathrm{s})$ \\
\hline 125 & 0.510 RT-0.708 \\
250 & 0.605 RT-0.867 \\
500 & 0.668 RT-0.929 \\
1000 & 0.696 RT-0.935 \\
2000 & 0.694 RT-0.889 \\
4000 & 0.652 RT-0.752 \\
\hline
\end{tabular}

TABLE 2: Recommended occupied reverberation times.

\begin{tabular}{lc}
\hline Type of music (speech) & Recommended RT (s) \\
\hline Organ music & $>2.5$ \\
Romantic classical music & $1.8-2.2$ \\
Early classical music & $1.6-1.8$ \\
Opera & $1.3-1.8$ \\
Chamber music & $1.4-1.7$ \\
Drama theatre & $0.7-1.0$ \\
\hline
\end{tabular}

each octave band is obtained by a backward integration of the squared impulse response. The impulse response is the temporal evolution of the sound pressure observed at a point in a room as a result of the emission of a Dirac impulse at another point in the room. It is impossible in practice to create and radiate true Dirac delta functions, but short transient sounds (e.g., from gunshots) can offer close enough approximations for practical measurement. An alternative measurement technique, however, is to use a deterministic, wide-band signal like a sine sweep and transform the measured response back to an impulse response. Several quantities that can be obtained from measured impulse responses are correlated with particular subjective aspects of the acoustical character of an auditorium [4].

The reverberation time (RT) is the basic indicator of acoustical behavior and is the time required for the EDC to decay by $60 \mathrm{~dB}$. It can be evaluated on a smaller dynamic range than $60 \mathrm{~dB}$ and then extrapolated to a $60 \mathrm{~dB}$ decay time. It is then labeled accordingly. Thus, if RT is derived from the average slope of the decay in the range between $5 \mathrm{~dB}$ and $25 \mathrm{~dB}$ below the initial level, it is accordingly labeled $T_{20}$. If the range is between $5 \mathrm{~dB}$ and $35 \mathrm{~dB}$, then the corresponding time is labeled $T_{30}$ [4].

If the RT is measured in an unoccupied room, then to obtain the value for the occupied one, the following correction should be made [8]:

$$
\mathrm{RT}_{o}=\mathrm{RT}-\mathrm{DT},
$$

where $\mathrm{RT}_{o}$ is the estimated RT when the enclosure is occupied and DT is the Schultz diffusion time, that is, the estimated change in RT values from the equations (see Table 1) $[8]$.

Barron [9] lists a range of recommended occupied reverberation times suited to different types of music or speech (Table 2).

In Table 2, the value quoted for the RT refers to the midfrequency value, averaged at 500 and $1000 \mathrm{~Hz}$. The "optimal" reverberation time depends on the type and style of the music $[1,10]$.

The early decay time (EDT) is defined as the reverberation time computed by the slope of the decay in the range between 0 and $-10 \mathrm{~dB}$ on the EDC [3]. The slope is evaluated by a linear regression line fitted over the appropriate portion of the decay curve [4]. The EDT is strongly influenced by early reflections, thus depends on the measuring position and the room's geometry. The associated subjective sensation of reverberation (perceived reverberation) is strongly correlated with EDT. The EDT is expected to have the same value as the reverberation time for a room exhibiting perfectly linear decay.

Clarity index $\left(C_{t_{e}}\right)$ is an early-to-late arriving sound energy rati

$$
C_{t_{e}}=10 \cdot \lg \left[\frac{\int_{0}^{t_{e}} h^{2}(t) \cdot d t}{\int_{t_{e}}^{\infty} h^{2}(t) \cdot d t}\right],
$$

where $t_{e}$ is the early time limit, specified to be either $50 \mathrm{~ms}$ or $80 \mathrm{~ms} ; C_{80}$ is usually considered relevant for music, $C_{50}$ for speech. The value for $C_{80}$ is obtained as the average of the $500 \mathrm{~Hz}, 1000 \mathrm{~Hz}$, and $2000 \mathrm{~Hz}$ values. It can range from small positive numbers for a dead room to small negative values for very reverberant spaces. Generally, the optimal value of $C_{80}$ for orchestral music is between 0 to $-3 \mathrm{~dB}$ and for singers it is between 1 and $5 \mathrm{~dB}$ [11].

Definition $\left(D_{50}\right)$ measures the early to total sound energy ratio. $D_{50}$ is mostly used for the speech case:

$$
D_{50}=\frac{\int_{0}^{50 \mathrm{~ms}} h^{2}(t) \cdot d t}{\int_{0}^{\infty} h^{2}(t) \cdot d t}[\%] .
$$

It is evaluated in the 4 octave frequency $(500 \mathrm{~Hz}, 1000 \mathrm{~Hz}$, $2000 \mathrm{~Hz}, 4000 \mathrm{~Hz}$ ) and should have values above 50\% for good speech intelligibility [12].

The center time $\left(T_{s}\right)$ corresponds to the center of gravity of the squared impulse response:

$$
T_{s}=\frac{\int_{0}^{\infty} t \cdot h^{2}(t) \cdot d t}{\int_{0}^{\infty} h^{2}(t) \cdot d t}[\mathrm{~s}] .
$$

$T_{s}$ avoids the discrete division of the impulse response into early and late periods [4]. For speech, the desirable $T_{s}$ is in the range of $60 \mathrm{~ms}-80 \mathrm{~ms}$ in the 4 relevant octave bands $(500 \mathrm{~Hz}$, $1000 \mathrm{~Hz}, 2000 \mathrm{~Hz}$, and $4000 \mathrm{~Hz}$ ). For music, the desirable $T_{s}$ is in the range of $70 \mathrm{~ms}-150 \mathrm{~ms}$ in the $1000 \mathrm{~Hz}$ octave band [12].

\subsection{Relation between Objective and Subjective Parameters.} Subjective studies of the acoustic characteristics of auditoria have shown that several quantities that can be obtained from measured impulse responses are correlated with particular subjective aspects of the acoustic character of an auditorium. While the reverberation time is a fundamental description of the acoustic character of an auditorium, the other quantities provide additional information on the acoustic conditions in the auditorium. Albeit dozens of additional acoustical descriptors have been defined, here only the parameters 
TABLe 3: Acoustical parameters and their JND values.

\begin{tabular}{lcc}
\hline Subjective listener aspect & $\begin{array}{c}\text { Acoustical } \\
\text { parameter }\end{array}$ & $\begin{array}{c}\text { Just noticeable } \\
\text { difference (JND) }\end{array}$ \\
\hline Perceived reverberance & EDT & $5 \%$ \\
Perceived clarity of sound & Clarity $C_{80}$ & $1 \mathrm{~dB}$ \\
& Definition $D_{50}$ & $5 \%$ \\
& $T_{s}$ & $10 \mathrm{~ms}$ \\
\hline
\end{tabular}

that have been found to be subjectively important and that can be obtained directly from integrating impulse responses are considered [4]. The just noticeable difference (JND) is the smallest change in a parameter that is necessary for a human to detect a difference. Table 3 presents the analyzed parameters and the associated JND values [4]. These values are computed at the midrange frequency (average at $500 \mathrm{~Hz}$ and $1000 \mathrm{~Hz}$ ).

\section{Measurement Setup and Software}

The acoustical parameter evaluation requires the following steps:

(i) Measure the room impulse response $h(t)$-in our experiments the following equipments were used.

(a) an omnidirectional microphone (PCB 130D20), having a diaphragm diameter of $7 \mathrm{~mm}$ (according to the ISO 3382, the microphone should have a maximum diaphragm diameter of $13 \mathrm{~mm}$ );

(b) a B\&K omnidirectional sound source type 4295 (dodecahedron loudspeaker);

(c) a B\&K audio power amplifier, rated at $100 \mathrm{~W}$ RMS, stereo, type 2716-C;

(d) a laptop, incorporating a Soundmax Integrated Digital Audio sound card from Analog Devices.

(ii) Measure the RT using the Delta Ohm HD 2010 sound lever meter/real-time spectrum analyzer, with the associated Delta Log 5 software that measures the RT values in octave frequency bands.

(iii) Estimation of the acoustical parameters-the processing of measurements was done with the $\mathrm{B} \& \mathrm{~K}$ Dirac software.

\section{The Evaluation of Acoustical Parameters in the Auditorium}

4.1. The Evaluated Points and Setups. The analyzed room is an auditorium of the Technical University of Cluj Napoca (Romania), with the volume of approximately $1326 \mathrm{~m}^{3}$, the walls are covered with absorbing materials as wood and plexiglass. The auditorium plan is presented in Figure 1. The furniture consists of wooden benches and seats; there are about 300 seats in the hall. The room was newly arranged
TABLE 4: Standard deviation of PNR (a) the source situated in S1 and (b) the source situated in S2.

(a)

\begin{tabular}{lcc}
\hline Frequency $(\mathrm{Hz})$ & $\begin{array}{c}\text { Average value } \\
\text { PNR }(\mathrm{dB})\end{array}$ & $\begin{array}{c}\text { Standard deviation } \\
\text { PNR }(\mathrm{dB})\end{array}$ \\
\hline 125 & 44 & 2 \\
250 & 49 & 2 \\
500 & 52 & 2 \\
1000 & 54 & 3 \\
2000 & 59 & 3 \\
4000 & 60 & 1 \\
\hline
\end{tabular}

(b)

\begin{tabular}{lcc}
\hline Frequency $(\mathrm{Hz})$ & $\begin{array}{c}\text { Average value } \\
\text { PNR }(\mathrm{dB})\end{array}$ & $\begin{array}{c}\text { Standard deviation } \\
\text { PNR }(\mathrm{dB})\end{array}$ \\
\hline 125 & 42 & 2 \\
250 & 49 & 1 \\
500 & 52 & 2 \\
1000 & 53 & 3 \\
2000 & 58 & 2 \\
4000 & 60 & 1 \\
\hline
\end{tabular}

as an auditorium; previously it was a sport room, so the acoustics had to be checked and if possible improved.

The impulse response measurements were performed using the instruments listed in the previous section and a $2.97 \mathrm{~s}$ linear sweep sine signal was applied. The advantages of the omnidirectional loudspeaker sound source measuring method are the omnidirectionality corresponding with ISO 3382 standard and good repeatability as well as ecological efficacy. The loudspeaker was placed at $1.50 \mathrm{~m}$ height above the floor in two positions: S1 and S2, indicated in Figure 1 by white large circles. The RT was also evaluated using a phonometer. The measurements were done in 15 spots pointed out by small white circles in Figure 1. The microphone was placed at a height of $1.2 \mathrm{~m}$ above the floor in the audience seat locations to respect the ISO 3382. In every spot, 5 measurements were made with both source positions and the resulting values are means of the measurements. The data processing was executed with the programs Dirac and Delta $\log 5$ (for phonometer).

4.2. Peak-to-Noise Ratio Analysis. The Peak-to-noise ratio (PNR) is defined as the difference between the maximum peak impulse response level and the root mean square (RMS) noise level, in $\mathrm{dB}$. It reflects the decay range, which according to ISO 3382 should be at least $35 \mathrm{~dB}$ or $45 \mathrm{~dB}$ for accurate determination of $T_{20}$ or $T_{30}$, respectively. Next to a visual inspection of the impulse response, the PNR can be used to judge the quality of a recording. Table 4 presents the PNR values for the analyzed samples for two source position.

The average value of the PNR at $125 \mathrm{~Hz}$ is below $45 \mathrm{~dB}$, value imposed by the ISO 3382 standard for T30 measurements. But due to the fact that the parameters are significant for frequencies above $500 \mathrm{~Hz}$ and for these frequencies PNR 


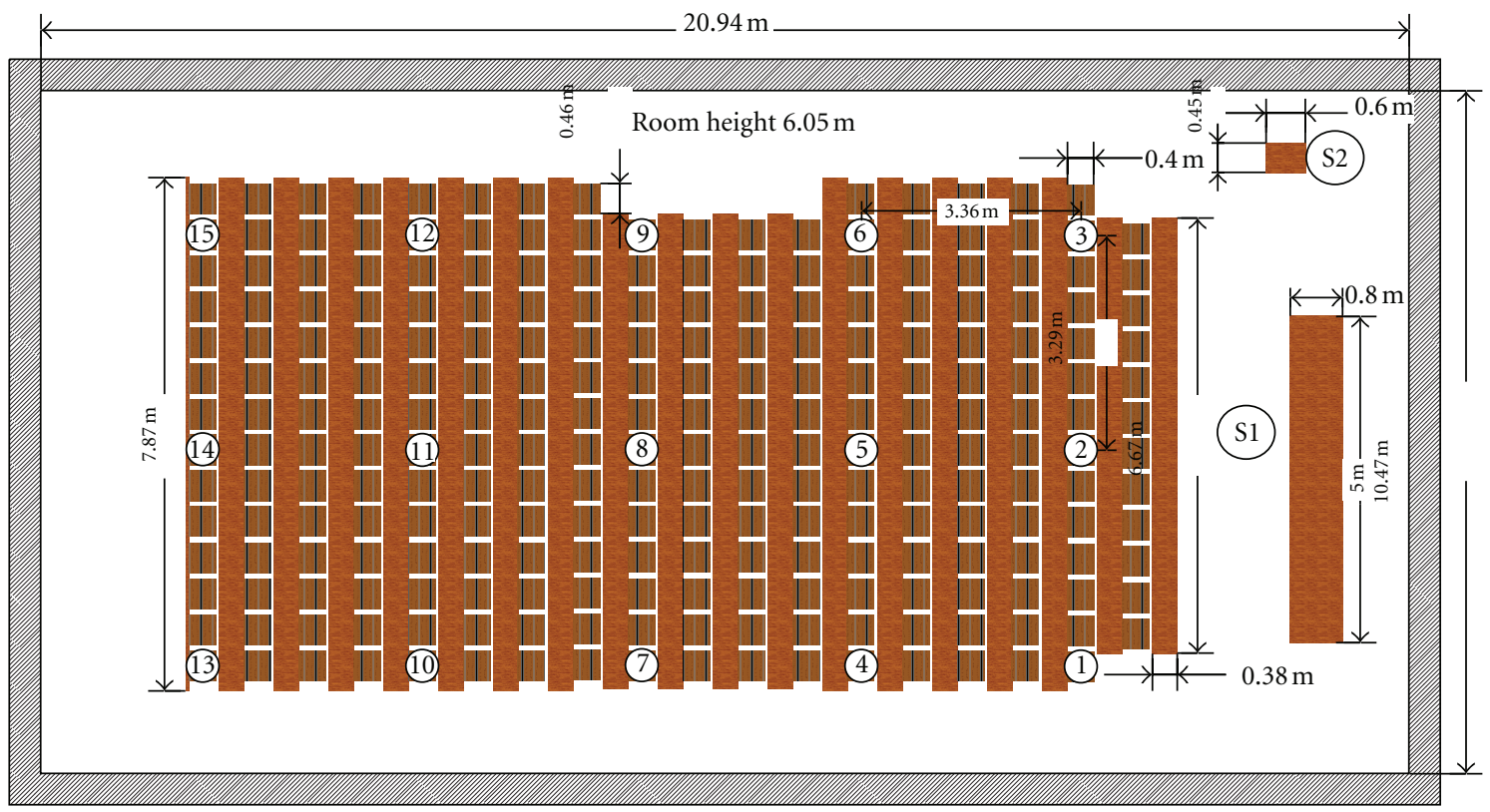

FIgURE 1: The plan of the auditorium.

TABLE 5: Standard deviation of reverberation time measured with an omnidirectional loudspeaker (a) the source situated in S1 and (b) the source situated in S2.

(a)

\begin{tabular}{lcc}
\hline $\begin{array}{l}\text { Frequency } \\
(\mathrm{Hz})\end{array}$ & $\begin{array}{c}\text { Average } \\
\text { value RT }(\mathrm{s})\end{array}$ & $\begin{array}{c}\text { Standard } \\
\text { deviation RT }(\mathrm{s})\end{array}$ \\
\hline 125 & 2.949 & 0.148 \\
250 & 3.017 & 0.095 \\
500 & 2.19 & 0.034 \\
1000 & 1.944 & 0.042 \\
2000 & 1.776 & 0.035 \\
4000 & 1.498 & 0.035 \\
\hline
\end{tabular}

(b)

\begin{tabular}{lcc}
\hline $\begin{array}{c}\text { Freq } \\
(\mathrm{Hz})\end{array}$ & $\begin{array}{c}\text { Average } \\
\text { value RT }(\mathrm{s})\end{array}$ & $\begin{array}{c}\text { Standard } \\
\text { deviation RT }(\mathrm{s})\end{array}$ \\
\hline 125 & 2.975 & 0.163 \\
250 & 3.026 & 0.137 \\
500 & 2.187 & 0.048 \\
1000 & 1.949 & 0.044 \\
2000 & 1.771 & 0.025 \\
4000 & 1.475 & 0.023 \\
\hline
\end{tabular}

exceeds $50 \mathrm{~dB}$, the acoustical evaluation of the room may be accomplished.

4.3. The Standard Deviation of Acoustical Parameters. The standard deviation of reverberation time was determined to provide a measure of accuracy and the spatial variance of the reverberation time. Their values are presented in Tables 5 and 6 , using the omnidirectional loudspeaker or the phonometer.
TABLE 6: Standard deviation of reverberation time measured with the HD 2010 SLM for the source situated in S1.

\begin{tabular}{lcc}
\hline $\begin{array}{c}\text { Freq } \\
(\mathrm{Hz})\end{array}$ & $\begin{array}{c}\text { Average } \\
\text { value RT }(\mathrm{s})\end{array}$ & $\begin{array}{c}\text { Standard } \\
\text { deviation RT }(\mathrm{s})\end{array}$ \\
\hline 125 & 3.048 & 0.158 \\
250 & 3.028 & 0.088 \\
500 & 2.144 & 0.039 \\
1000 & 1.945 & 0.028 \\
2000 & 1.829 & 0.022 \\
4000 & 1.569 & 0.017 \\
\hline
\end{tabular}

It is remarkable that the values of standard deviation from Tables 5 and 6 never exceed 1 JND, being around 2\% at $500 \mathrm{~Hz}$ and $1000 \mathrm{~Hz}$.

The standard deviation analysis for the other acoustical parameters for the same frequencies, $500 \mathrm{~Hz}$ and $1000 \mathrm{~Hz}$, is presented in Tables $7,8,9,10,11,12,13$, and 14 . The 0.00 value from Tables 9, 11, and 12 denotes a standard deviation below 0.01 . None of the measured values from Tables 7-14 exceeds 1 JND.

4.4. Estimation of the Reverberation Time in the Occupied Room. Using relation (2) one can estimate the occupied reverberation time: $\mathrm{RT}_{o}=1.59 \mathrm{~s}$ independently of the source position or evaluation equipment. The value of RT places the auditorium in the category of rooms which are designed to opera and chamber music events. It is generally considered tolerable, if not favorable, to have an increase of the RT in the low frequency range (below $500 \mathrm{~Hz}$ ). On the other hand, there are several concert halls with RTs which do not increase at low frequencies or which even have a slightly decreasing RT and are considered to be excellent from an acoustical 
TABLE 7: Standard deviation of EDT for the source situated in S1.

\begin{tabular}{lcccccccccccccccc}
\hline$f(\mathrm{~Hz})$ & & \multicolumn{1}{c}{ Standard deviation EDT (s) - S1 } \\
& 1 & 2 & 3 & 4 & 5 & 6 & 7 & 8 & 9 & 10 & 11 & 12 & 13 & 14 & 15 \\
\hline 500 & 0.002 & 0.014 & 0.008 & 0.028 & 0.003 & 0.012 & 0.012 & 0.017 & 0.007 & 0.004 & 0.005 & 0.009 & 0.008 & 0.009 & 0.004 \\
1000 & 0.001 & 0.002 & 0.008 & 0.081 & 0.006 & 0.005 & 0.008 & 0.014 & 0.007 & 0.003 & 0.001 & 0.02 & 0.005 & 0.005 & 0.009 \\
\hline
\end{tabular}

TABLE 8: Standard deviation of EDT for the source situated in S2.

\begin{tabular}{lcccccccccccccccc}
\hline$f(\mathrm{~Hz})$ & & \multicolumn{1}{c}{ Standard deviation EDT (s) - S2 } \\
& 1 & 2 & 3 & 4 & 5 & 6 & 7 & 8 & 9 & 10 & 11 & 12 & 13 & 14 & 15 \\
\hline 500 & 0.005 & 0.011 & 0.005 & 0.004 & 0.002 & 0.006 & 0.005 & 0.009 & 0.008 & 0.006 & 0.005 & 0.006 & 0.005 & 0.007 & 0.009 \\
1000 & 0.004 & 0.007 & 0.003 & 0.007 & 0.015 & 0.006 & 0.015 & 0.015 & 0.006 & 0.008 & 0.01 & 0.007 & 0.01 & 0.004 & 0.014 \\
\hline
\end{tabular}

TABLE 9: Standard deviation of $C_{80}$ for the source situated in S1.

\begin{tabular}{lccccccccccccccc}
\hline$f(\mathrm{~Hz})$ & \multicolumn{10}{c}{} & \multicolumn{11}{c}{ Standard deviation $C_{80}(\mathrm{~dB})-\mathrm{S} 1$} \\
& 1 & 2 & 3 & 4 & 5 & 6 & 7 & 8 & 9 & 10 & 11 & 12 & 13 & 14 & 15 \\
\hline 500 & 0.01 & 0.02 & 0.01 & 0.03 & 0.03 & 0.02 & 0.01 & 0.07 & 0.02 & 0.01 & 0.01 & 0.02 & 0.01 & 0.02 & 0.01 \\
1000 & 0.01 & 0.01 & 0.02 & 0.08 & 0.01 & 0.02 & 0.03 & 0.05 & 0.05 & 0.05 & 0.04 & 0.02 & 0.04 & 0.00 & 0.04 \\
\hline
\end{tabular}

TABLE 10: Standard deviation of $C_{80}$ for the source situated in S2.

\begin{tabular}{lccccccccccccccc}
\hline$f(\mathrm{~Hz})$ & & \multicolumn{1}{c}{ Standard deviation $C_{80}(\mathrm{~dB})-\mathrm{S} 2$} \\
& 1 & 2 & 3 & 4 & 5 & 6 & 7 & 8 & 9 & 10 & 11 & 12 & 13 & 14 & 15 \\
\hline 500 & 0.01 & 0.03 & 0.01 & 0.02 & 0.01 & 0.01 & 0.04 & 0.04 & 0.02 & 0.03 & 0.01 & 0.03 & 0.08 & 0.03 & 0.02 \\
1000 & 0.02 & 0.02 & 0.01 & 0.03 & 0.01 & 0.01 & 0.09 & 0.05 & 0.03 & 0.03 & 0.03 & 0.03 & 0.02 & 0.04 & 0.03 \\
\hline
\end{tabular}

TABLE 11: Standard deviation of $D_{50}$ for the source situated in S1.

\begin{tabular}{lccccccccccccccc}
\hline$f(\mathrm{~Hz})$ & & \multicolumn{1}{c}{ Standard deviation $D_{50}(\%)-\mathrm{S} 1$} \\
& 1 & 2 & 3 & 4 & 5 & 6 & 7 & 8 & 9 & 10 & 11 & 12 & 13 & 14 & 15 \\
\hline 500 & 0.00 & 0.00 & 0.00 & 0.01 & 0.00 & 0.00 & 0.00 & 0.00 & 0.00 & 0.00 & 0.00 & 0.00 & 0.00 & 0.00 & 0.00 \\
1000 & 0.00 & 0.00 & 0.00 & 0.01 & 0.00 & 0.00 & 0.00 & 0.00 & 0.00 & 0.00 & 0.00 & 0.00 & 0.00 & 0.00 & 0.00 \\
\hline
\end{tabular}

TABLE 12: Standard deviation of $D_{50}$ for the source situated in $S 2$.

\begin{tabular}{lccccccccccccccc}
\hline$f(\mathrm{~Hz})$ & 1 & \multicolumn{1}{c}{ Standard deviation $D_{50}(\%)-\mathrm{S} 2$} \\
& 1 & 2 & 3 & 4 & 5 & 6 & 7 & 8 & 9 & 10 & 11 & 12 & 13 & 14 & 15 \\
\hline 500 & 0.00 & 0.00 & 0.00 & 0.00 & 0.00 & 0.00 & 0.00 & 0.00 & 0.00 & 0.00 & 0.00 & 0.00 & 0.00 & 0.00 & 0.00 \\
1000 & 0.00 & 0.00 & 0.00 & 0.00 & 0.00 & 0.00 & 0.00 & 0.00 & 0.00 & 0.00 & 0.00 & 0.00 & 0.00 & 0.00 & 0.00 \\
\hline
\end{tabular}

TABLE 13: Standard deviation of $T_{s}$ for the source situated in S1.

\begin{tabular}{lccccccccccccccc}
\hline \multirow{2}{*}{$(\mathrm{Hz})$} & 1 & \multicolumn{1}{c}{ Standard deviation $T_{s}(\mathrm{~ms})-\mathrm{S} 1$} \\
& 1 & 2 & 3 & 4 & 5 & 6 & 7 & 8 & 9 & 10 & 11 & 12 & 13 & 14 & 15 \\
\hline 500 & 0.1 & 0.5 & 0.2 & 1 & 0 & 0.3 & 0.4 & 0.3 & 0.2 & 0.1 & 0.3 & 0.2 & 0.3 & 0.2 & 0.1 \\
1000 & 0.1 & 0.1 & 0.2 & 1.8 & 0.1 & 0.2 & 0.2 & 0.3 & 0.5 & 0.4 & 0.1 & 0.9 & 0.1 & 0.2 & 0.3 \\
\hline
\end{tabular}

TABLE 14: Standard deviation of $T_{s}$ for the source situated in S2.

\begin{tabular}{lccccccccccccccc}
\hline$f(\mathrm{~Hz})$ & \multicolumn{1}{c}{} & \multicolumn{11}{c}{ Standard deviation $T_{s}(\mathrm{~ms})-\mathrm{S} 2$} \\
& 1 & 2 & 3 & 4 & 5 & 6 & 7 & 8 & 9 & 10 & 11 & 12 & 13 & 14 & 15 \\
\hline 500 & 0.3 & 0.3 & 0.1 & 0.1 & 0.1 & 0.1 & 0.2 & 0.6 & 0.1 & 0.4 & 0.3 & 0.2 & 0.1 & 0.5 & 0.2 \\
1000 & 0.1 & 0.2 & 0.1 & 0.5 & 0.5 & 0.1 & 0.4 & 1.1 & 0.2 & 0.4 & 0.4 & 0.4 & 0.4 & 0.4 & 0.2 \\
\hline
\end{tabular}



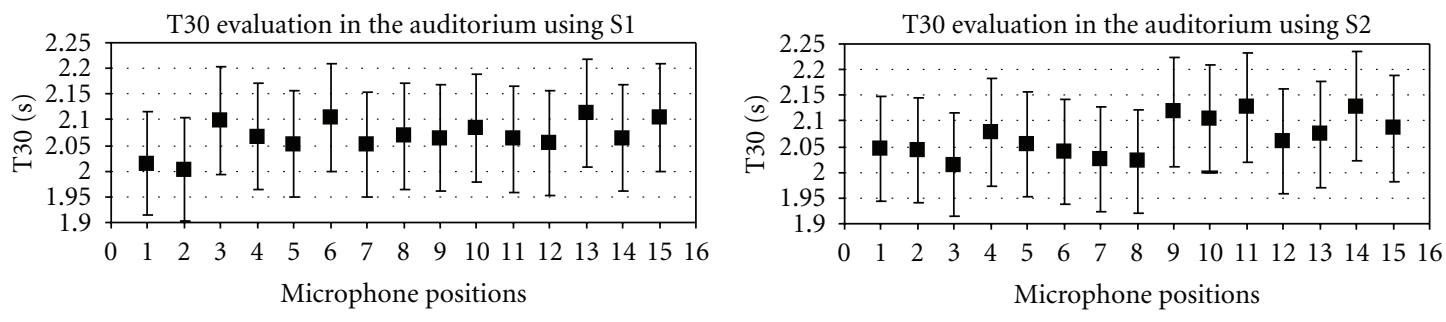

$\begin{array}{lll}-\mathrm{T} 30+\mathrm{JND} & \mathrm{T} 30 \quad \mathrm{~T} 30-\mathrm{JND}\end{array}$

$\begin{array}{lll}-\mathrm{T} 30+\mathrm{JND} & \mathrm{T} 30 \quad \mathrm{~T} 30-\mathrm{JND}\end{array}$
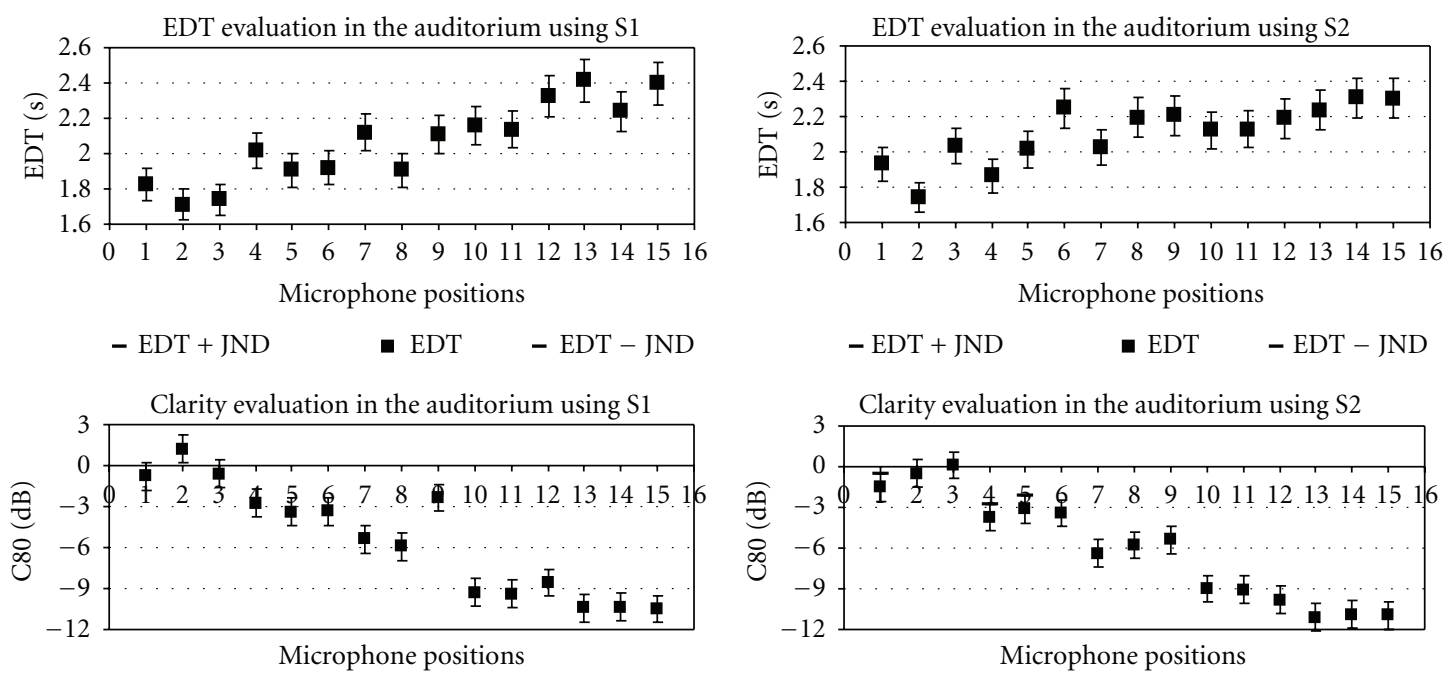

$-\mathrm{C} 80+\mathrm{JND} \quad$ - $\mathrm{C} 80 \quad-\mathrm{C} 80-\mathrm{JND}$

- $\mathrm{C} 80+\mathrm{JND}$

- C80

- $\mathrm{C} 80-\mathrm{JND}$
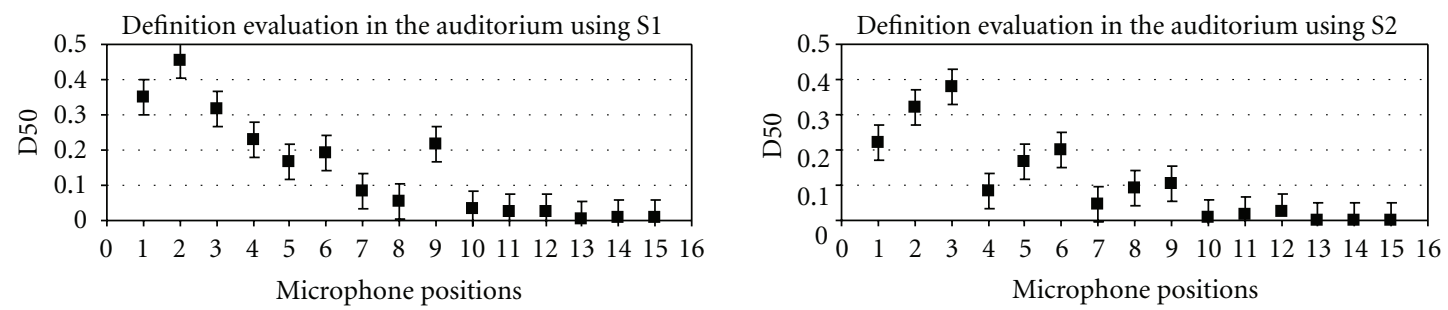

- D50 + JND - D50 - D50 - JND

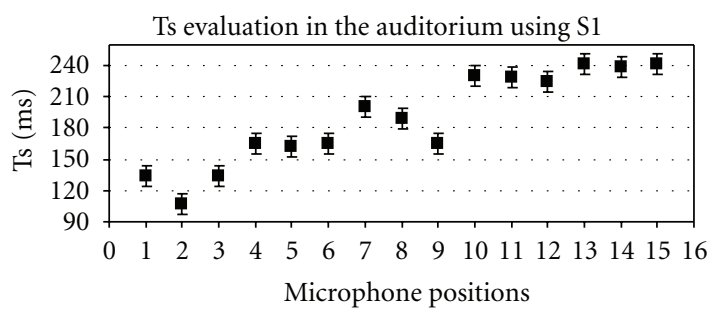

$-\mathrm{D} 50+\mathrm{JND}$

- D50 - D50 - JND

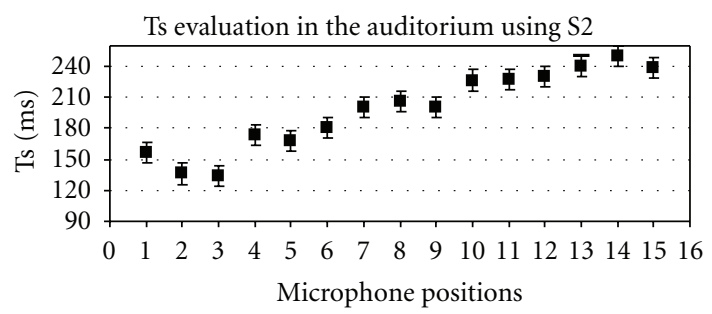

$\begin{array}{lll}-\mathrm{Ts}+\mathrm{JND} & \text { - Ts } & -\mathrm{Ts}-\mathrm{JND}\end{array}$

(a)

$\begin{array}{lll}-\mathrm{T}+\mathrm{JND} & \mathrm{Ts} & \mathrm{Ts}\end{array}$

(b)

FIGURE 2: Measured acoustical parameters in the microphone positions and their JND values (indicated by error bars) for (a) the S1 source position and (b) the S2 source position.

point of view [1]. For speech, a decrease of RT is desirable in this frequency range $[9,12]$. Due to the increased values of reverberation time at low frequencies (below $500 \mathrm{~Hz}$ ), a "warmth" sensation for music will appear in this auditorium.
4.5. Diffusion Analysis. The diffuseness or directedness of enclosures is indicated by $\mathrm{EDT} / \mathrm{T}_{30}$ ratio at mid frequencies. For the audience, a lack of diffusion may be heard as poor balance and blend between the various sections [9]. In 


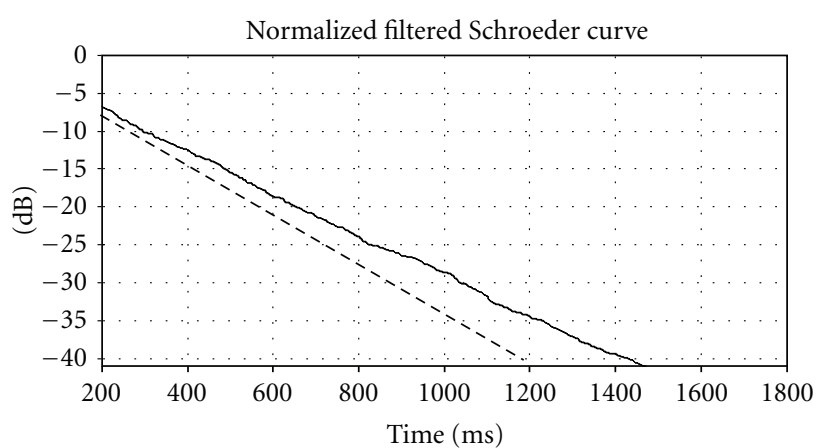

- Decay curve - - Slope of EDT

(a)

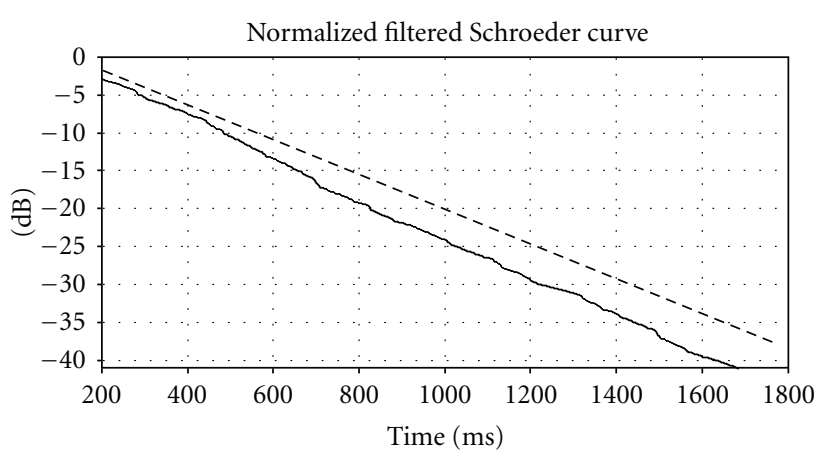

- Decay curve

(b)

FIgURe 3: Decay curves for (a) the 2nd microphone position and (b) the 13th microphone position.

TABLE 15: EDT/ $T_{30}$ ratio for the source situated in S1.

\begin{tabular}{|c|c|c|c|c|c|c|c|c|c|c|c|c|c|c|c|}
\hline $\begin{array}{l}\text { Microphone } \\
\text { position }\end{array}$ & 1 & 2 & 3 & 4 & 5 & 6 & 7 & 8 & 9 & 10 & 11 & 12 & 13 & 14 & 15 \\
\hline $\mathrm{EDT} / T_{30}$ & 0.91 & 0.85 & 0.83 & 0.98 & 0.93 & 0.91 & 1.03 & 0.92 & 1.02 & 1.04 & 1.04 & 1.13 & 1.14 & 1.09 & 1.14 \\
\hline
\end{tabular}

TABLE 16: $\mathrm{EDT} / T_{30}$ ratio for the source situated in $\mathrm{S} 2$.

\begin{tabular}{|c|c|c|c|c|c|c|c|c|c|c|c|c|c|c|c|}
\hline $\begin{array}{l}\text { Microphone } \\
\text { position }\end{array}$ & 1 & 2 & 3 & 4 & 5 & 6 & 7 & 8 & 9 & 10 & 11 & 12 & 13 & 14 & 15 \\
\hline $\mathrm{EDT} / T_{30}$ & 0.94 & 0.85 & 1.01 & 0.90 & 0.98 & 1.10 & 1.00 & 1.09 & 1.04 & 1.01 & 1.00 & 1.06 & 1.08 & 1.08 & 1.10 \\
\hline
\end{tabular}

a highly diffuse hall, where the decay is completely linear, the $\mathrm{EDT} / T_{30}$ ratio tends to have a value close to 1 , that means that EDT and RT are almost equal $[9,13]$. The mean value of EDT/ $T_{30}$ gives a global evaluation of the diffuseness or directedness. Good diffuseness is obtained when the mean $\mathrm{EDT} / \mathrm{T}_{30}$ ratio takes values between 0.8 and 1.1 [13]. In the case of the auditorium, the mean $\mathrm{EDT} / \mathrm{T}_{30}$ ratio for $\mathrm{S} 1$ is $0.9973 \mathrm{~s}$ and for S2 is $1.0160 \mathrm{~s}$ (almost ideal values).

Particularly, using the microphone positions dependent $\mathrm{EDT} / \mathrm{T}_{30}$ ratio, one can determine prominent directional or diffuse locations. Regarding to the spatial variation of EDT (Figure 2), a general conclusion can be made: where the EDT has maximal values, the locations are diffuse (the EDT/ $T_{30}$ values are close to 1.1 ), whereas minimal values indicate a directional sound field. This assertion can be made due to the relative constant spatial RT. Tables 15 and 16 present $\mathrm{EDT} / T_{30}$ ratios for both source positions. From the tables one can conclude that the auditorium is diffuse and does not have excessively directional spots (the ratio is above 0.8 ). Three excessively diffuse locations were found for the S1 source position $(12,13$, and 15) and for S2 position a single location was identified.

In a directed design in which early sound is reflected into the audience, where a sagging decay is obtained, the $\mathrm{EDT} / \mathrm{T}_{30}$ ratio tends to be lower than 1 . Ballooning decay indicates an $\mathrm{EDT} / \mathrm{T}_{30}$ ratio that exceeds 1 , so the enclosure is described as excessively diffuse $[13,14]$. Figure 3 (a) presents the decay curve for the 2 nd microphone position, where
EDT $<T_{30}$ reveals a sagging decay. Figure $3(\mathrm{~b})$ indicates the decay of the 13th microphone position where EDT $>T_{30}$ exposes a ballooning decay at $500 \mathrm{~Hz}$. The slope of the EDT is presented by a parallel dashed line to the decay curve.

4.6. JND Analysis. Accurate evaluation of acoustical parameters can be achieved with the examination of spatial variations as well as their JND values. It is a useful way to model the room acoustics using reverberators. Reverberators are spatial effect generators [15]. Because we cannot build a reverberator for every point in the measured space, one have to try to reduce the implementation complexity using the JND terms.

Let us recall Figure 2 to illustrate the acoustical parameters and their JND values for mid-frequency range (average $500 \mathrm{~Hz}$ and $1000 \mathrm{~Hz}$ ) and also two offset values marked with error bars, one with the measured values +JND, the other is the measured value -JND. This plots make it easy to understand if the spatial variation of the parameter is significant or not as well as their perceptually aspects. The EDT and $T_{s}$ are correlated, whereas EDT is inverse correlated with $C_{80}$; similar results were found in $[9,13]$. The sensitivity of the acoustical parameters to the source positions at mid frequencies are observed by comparing the two columns of Figure 2.

(i) For $T_{30}$, one cannot found any locations where the variations exceed 1 JND for the two excitation locations; 
(ii) EDT has a variation that exceeds 1 JND for the following locations: $1,3,4,5,6,8,12$, and 13;

(iii) $C_{80}$ has a variation that exceeds 1 JND for the following locations: 2, 9, and 12;

(iv) $D_{50}$ has a variation that exceeds 1 JND for the following locations: 1, 2, 3, 4, and 9;

(v) $T_{s}$ has a variation that exceeds 1 JND for the following locations: $1,2,6,8,9$, and 14 .

For the auditorium, the center time is the most sensitive acoustical parameter and the clarity is the least sensitive with respect to the excitation source position.

An enhanced evaluation and analyses are obtained by pairing of acoustical parameters based on perceived reverberation and clarity. One can try to identify a number of regions in the room where EDT and clarity are the same (the variation of the acoustical parameters not exceeding 1 JND) (Figure 2). This can be achieved separately for S1 and S2 or together for the two source positions.

Considering the source placed in S1, one can find 11 regions with the same subjective reverberation and clarity sensation. To model these acoustical features, 11 reverberators are necessary instead of 15 (the total number of considered measuring positions); this means a reduction of $26.66 \%$.

If the source is placed in S2, we obtained 9 regions with the same subjective reverberation and clarity sensation. In this case, the acoustical modeling will require 9 reverberators instead of 15 , that is, a reduction of $40 \%$.

If we want to consider the source placed to S1 or S2, we obtained 12 regions, so a reduction of the necessary reverberators is of $20 \%$.

One can observe that the reduction in this last case is lower than in the previous cases. This is due to the huge acoustical differences between samples of regions, for instance, the samples situated at the front of the hall with respect to the end ones.

\section{Conclusions}

The paper presents the acoustical evaluation of an auditorium using an omnidirectional loudspeaker for sound source and linear sweep sine signal for excitation. The hall was evaluated for 2 source positions. For the evaluation of the reverberation time, a phonometer was also used for one source position. We did not detect important differences between the reverberation times determined in the 2 source positions with the omnidirectional loudspeaker and with the phonometer. We made 5 measurements in each spot to check the repeatability. Notable standard deviation differences were not found.

Taking into account the values of the reverberation time, the possible destination of the room is for opera and chamber music events. The auditorium has poor acoustical properties for speech events (like lectures, courses). At the same time, the hall has many diffuse locations.

Using 2 subjective criteria (the perceived reverberation and clarity), a number of 11 and 9 perceptively identical locations were found for individual source position and 12 locations if the sources are considered together. This fact indicates the possibility of acoustical model optimization.

\section{Acknowledgments}

This work was supported by the Romanian National University Research Council under Grant no. 2534 and by the European Social Fund under Grant no. POSDRU/89/1.5/S/52603, entitled "Development and support of multidisciplinary postdoctoral programmes in major technical areas of national strategy of Research-Development-Innovation” 4DPOSTDOC.

\section{References}

[1] H. Kuttruff, Room Acoustics, Spon Press, London, UK, 2009.

[2] F. Alton Everest, Master Handbook of Acoustics, McGraw-Hill, Two Penn Plaza, NY, USA, 4th edition, 2001.

[3] M. Kahrs and K. Brandenburg, Applications of Digital Signal Processing to Audio and Acoustics, Kluwer Academic Publishers, Norwell, Mass, USA, 1998.

[4] ISO 3382-1:2009, "Acoustics—measurement of room acoustic parameters-part 1: performance spaces".

[5] A. Farina, "Impulse response measurements," in Proceedings of the 23rd Nordic Sound Symposium Training and Information Seminar for Audio People, pp. 1-31, September 2007, http:// pcfarina.eng.unipr.it/Public/Papers/238-NordicSound2007 .pdf.

[6] R. Stewart and M. Sandler, "Statistical measures of early reflections of room impulse responses," in Proceedings of the 10th International Conference on Digital Audio Effects (DAF'07), pp. 59-62, Bordeaux, France, September 2007, http://dafx.labri.fr/ main/dafx07-proc.pdf.

[7] M. Holters, T. Corbach, and U. Zölzer, "Impulse response measurement techniques and their applicability in the real world," in Proceedings of the 12th International Conference on Digital Audio Effects (DAF '09), pp. 1-5, Como, Italy, September 2009, http://dafx09.como.polimi.it/proceedings/ data/DAFx09_Proceedings.pdf.

[8] J. S. Bradley, "A comparison of three classical concert halls," Journal of the Acoustical Society of America, vol. 89, no. 3, pp. 1176-1192, 1991.

[9] M. Barron, Auditorium Acoustics and Architectural Design, Taylor \& Francis, 2nd edition, 2009.

[10] N. W. Adelman-Larsen, E. R. Thompson, and A. C. Gade, "Suitable reverberation times for halls for rock and pop music," Journal of the Acoustical Society of America, vol. 127, no. 1, pp. 247-255, 2010.

[11] T. Hidaka and L. L. Beranek, "Objective and subjective evaluations of twenty-three opera houses in Europe, Japan, and the Americas," Journal of the Acoustical Society of America, vol. 107, no. 1, pp. 368-383, 2000.

[12] G. M. Ballou, Handbook for Sound Engineers, Elsevier, 2005.

[13] M. Barren, "Using the standard on objective measures for concert auditoria, ISO 3382, to give reliable results," Acoustical Science and Technology, vol. 26, no. 2, pp. 162-169, 2005.

[14] M. Barron, "Early decay times in the Christchurch and Wellington concert halls, New Zealand," Journal of the Acoustical Society of America, vol. 103, no. 4, pp. 2229-2231, 1998.

[15] N. Toma, M. D. Topa, V. Popescu, and E. Szopos, "Comparative performance analysis of artificial reverberation algorithms," in Proceedings of IEEE International Conference on Automation, Quality and Testing, Robotics (AQTR '06), pp. 138-142, Cluj-Napoca, Romania, May 2006. 

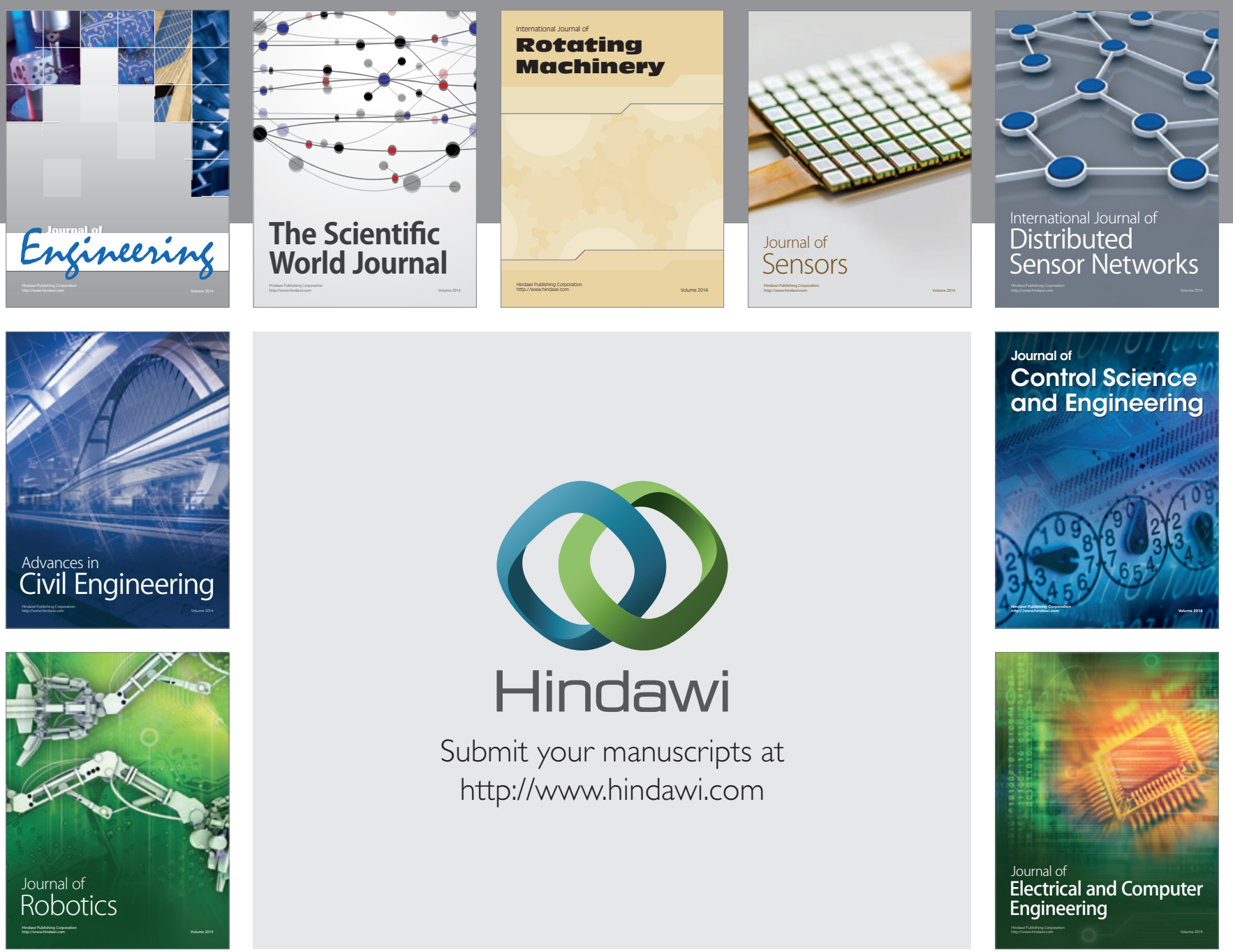

Submit your manuscripts at

http://www.hindawi.com
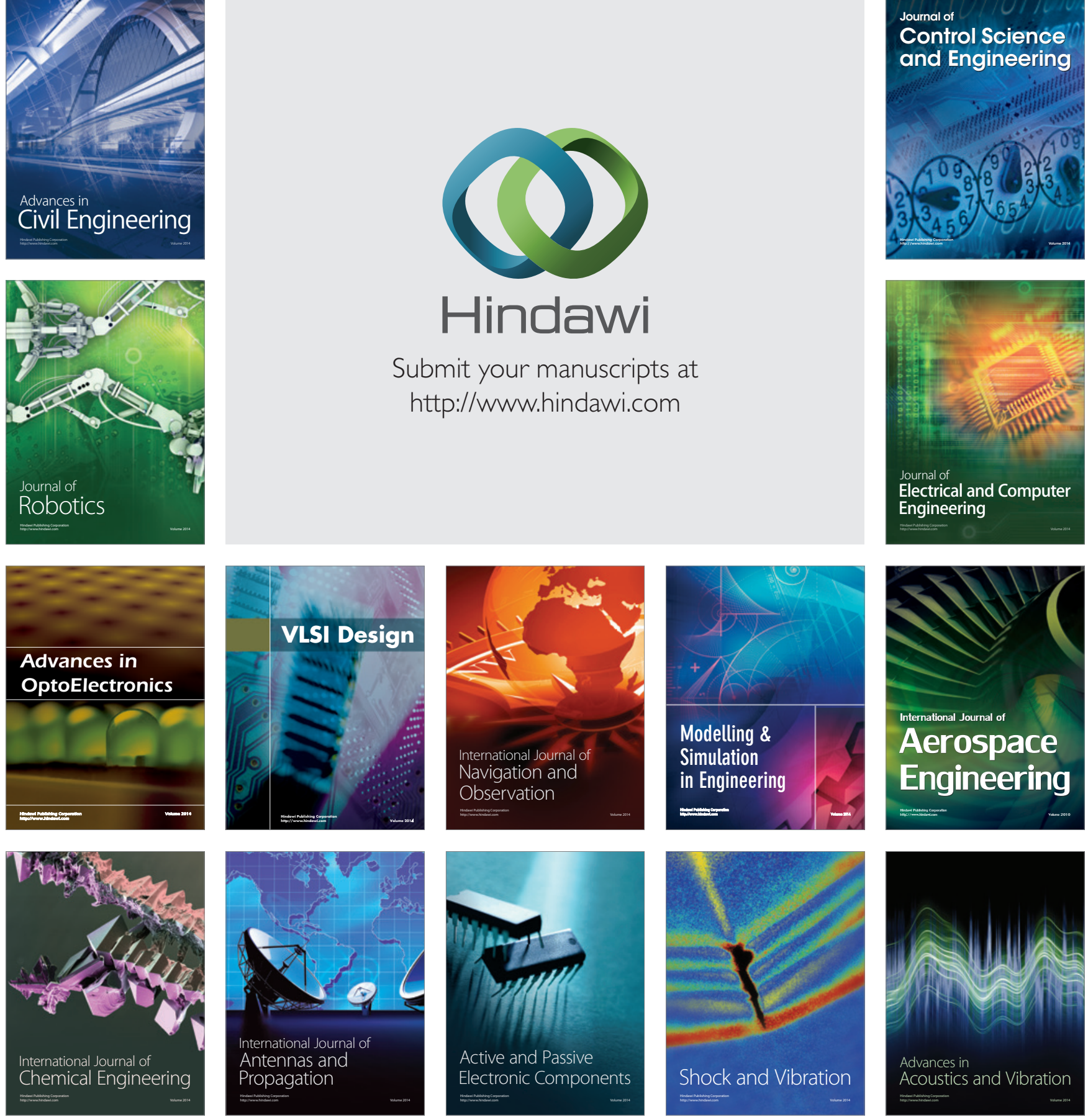